\title{
Treatise on optical physics
}

\section{A. B. Basset}

To cite this article: A. B. Basset (1892) Treatise on optical physics, Philosophical Magazine Series 5, 34:209, 386-387, DOI: 10.1080/14786449208620335

To link to this article: http://dx.doi.org/10.1080/14786449208620335

\section{Published online: 08 May 2009.}

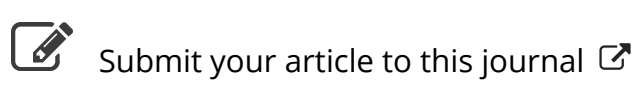

\footnotetext{
Џll Article views: 2
}

Q View related articles ¿ 


\section{$\left[\begin{array}{ll}386 & ]\end{array}\right.$ \\ XLV. Intelligence and Miscellaneous Articles. TREATISE ON OPTICAL PHYSICS.}

To the Editors of the Philosophical Magazine and Journal.

\section{Gentuemen,}

United University Club, August 4th, 1892.

$\mathbf{I}^{\mathrm{T}}$ be regretted that the anonymous author of the review of on Physical Optics has not adopted the manly and ightforward course of appending his name to the review. No reasonable persun can complain of legitimate criticism; but surely those principles of fair play, which bappily prevail amongst English gentlemen, require that an assailant who has made rather a severe attack upon my book should disclose his identity.

It would be hazardous to speculate whether the anonymous reviewer belongs to a school of thought which has on more than one occasion come forward as the satirist of Cambridge Mathematics, and which, if I mistake not, has its beadquarters in the capital of the northern portion of this Island; or whether he hails from a part of the United Kingdom whose political constitution will shortly be the subject of much discussion. If, however, he will lay aside the bias which he evidently entertains against Cambridge text-books, and will read more carefully the work of one who still looks back with gratifude upon the admirable system of instruction provided by the University of Cambridge, I think he will find that the "skeleton" is by no means devoid of flesh, nor is it in a state of nudity.

The ancient school of investigators postulated the existence of a medium, or æther; but their ideas were not sufficiently clear to enable them to construct a satisfactory dynamical theory. They succeeded, however, in explaining a variety of phenomena relating to isotropic media; they discovered the form of the wave-surface in biaxal crystals; and they accounted for the production of coloured rings by thin crystalline plates. But I should be very much surprised to find any modern physicist who would attempt to justify the dynamical reasoning upon which Fresnel attempted to base his theory; and there are grounds for thinking that he originally discovered his wave-surface by an inductive method, founded upon the construction of Huygens' for uniaxal crystals.

The modern school of investigators commenced with Green, who did the one thing I bave so strongly insisted upon, and which the anonymuus reviewer describes as the foolish process of writing down equations. Green formulated a definite hypothesis concerning the physical constitution of the rther; be thereby obtained the equations of motion of the medium ; and he solved them both in the case of an isotropic medium and a doubly refracting one. Further research has undoubtedly shown that Green's theory is defective, since it furnishes several results which are inconsistent with experiment; but the fact that Green did write down his 
equations and integrate them, enabled a variety of results to be explained which altogether puzzled the older investigators, and would probably have remained a mystery to this day had it not been for the industry and skill of the despised mathematicians.

If the ayonymous reviewer will read through chapters XI., XIV., and $x v$, he will find that the physical constitution of the rether according to Green's theory, and also according to Lord Kelvin's modification of Lord Rayleigh's theory, is fully explained; and that the principal mathematical developments are given, and discussed in relation to experimental phenomena. What more can he want?

The next stage in the history of the subject consists in the attempt to account for dispersion and absorption by means of the mutual reaction between wther and matter. The physical idea which lies at the root of such theories is so exceedingly simple, that it would be difficult for a person afflicted with the most exuberant verbosity to write more than a page or two of general talk upon the subject. The real difficulty lies in attempting to express this idea in a mathematical form, as will be seen by consulting the somewhat voluminous German literature upon the subject. I decided, after some consideration, to confine myself to the theories of Lord Kelvin and von Helmholtz. The former theory is especially valuable, because it enables us to construct a mechanical model of a medium which produces anomalous dispersion; whilst the latter theory, besides giving a partial explanation of selective reflexion, enables us to place Cauchy's formula for metallic reflexion on a dynamical basis.

In conclusion, I will give an example which shows how necessary it is to cover up the nakedness of the physical skeleton with mathematical clothing. Many years ago the hypothesis was formulated (by Lord Kelvin, I believe) that magnetic force was the effect of something in the nature of rotation. So far so good; but in the absence of the fructifying influence of mathematical analysis the idea would have remained as barren as a seed lying in the desert. There is no $\dot{a}$ priori reason for supposing that rotation of the medium would produce rotation of the plane of polarization of athereal waves; for it might equally well have happened that it would change a plane-polarized wave into a single elliptically polarized wave. But, thanks to mathematical analysis, we now know that rotation of the plane of polarization is a necessary consequence of rotation of the medium.

The reviewer bas finally come forward as an authority on style. How far he is competent to assume that character may be judged from the following quotations :- "But, as the author in his preface says" (then follows a passage from my book concluding with a full stop). "This last, by the way, is one of the extraordinary statements." "The entirely admirable text-book of Mr. Preston."

I am, Gentlemen,

Your obedient Servant,

A. B. Basset. 